\title{
The relationship between cryptocurrencies and COVID-19 pandemic
}

\author{
Ender Demir ${ }^{1,2} \cdot$ Mehmet Huseyin Bilgin $^{3}$ - Gokhan Karabulut ${ }^{4}$. \\ Asli Cansin Doker ${ }^{5}$
}

Received: 2 June 2020 / Revised: 9 July 2020 / Accepted: 16 July 2020 / Published online: 29 July 2020

(c) Eurasia Business and Economics Society 2020

\begin{abstract}
We examine the relationship between cryptocurrencies (namely Bitcoin (BTC), Ethereum (ETH), and Ripple (XRP)) and COVID-19 cases/deaths. This will help explore whether cryptocurrencies can serve as a hedge against COVID-19. The wavelet coherence analysis indicates that there is initially a negative relationship between Bitcoin and the number of reported cases and deaths; however, the relationship becomes positive during the later period. The findings for Ethereum and Ripple are also similar but with weaker interactions. This supports the hedging role of cryptocurrencies against the uncertainty raised by COVID-19.
\end{abstract}

Keywords Bitcoin $\cdot$ Ethereum $\cdot$ Ripple $\cdot$ Wavelet coherence $\cdot$ COVID-19

Ender Demir

ender.demir@medeniyet.edu.tr

Mehmet Huseyin Bilgin

mehmet.bilgin@medeniyet.edu.tr

Gokhan Karabulut

gbulut@istanbul.edu.tr

Asli Cansin Doker

acdoker@erzincan.edu.tr

1 University of Social Sciences, Lodz, Poland

2 Istanbul Medeniyet University, Istanbul, Turkey

3 Faculty of Political Science, Istanbul Medeniyet University, Istanbul, Turkey

4 Faculty of Economics, Istanbul University, Istanbul, Turkey

5 Faculty of Economics and Administrative Sciences, Erzincan Binali Yildirim University,

Erzincan, Turkey 


\section{Introduction}

Coronavirus (COVID-19) outbreak, which began in Wuhan, China, has rapidly spread all over the world infecting millions of people and causing thousands of deaths. World Health Organization declared this outbreak a global pandemic. The governments are implementing several restrictions such as travel bans, school closures, and curfews, and the lives of billions are affected.

The interest of the financial researchers on the impacts of COVID-19 on financial markets is rapidly rising. Onali (2020) explores the effect of COVID-19 cases and deaths on Dow Jones and S\&P500 indexes. He finds that the number of infections and deaths in Italy, Spain, the UK, Iran, and France does not affect the stock market returns except for the number of reported cases in China. Al-Awadhi et al. (2020) focus on the Chinese stock market and document that both the daily growth in reported cases and the increasing number of deaths caused by COVID19 lead to a decrease in stock returns. Zhang et al. (2020) show that the uncertainty raised by COVID-19 makes stock markets more volatile and unpredictable. Corbet et al. (2020) explore the volatility relationship between the Chinese stock markets and Bitcoin. This relationship becomes significantly tighter during the Covid-19 period. Zaremba et al. (2020) explore the association between policy responses to the COVID-19 pandemic and stock market volatility. It is documented that stringent policy responses cause a rise in return volatility.

In this paper, we use daily US\$ prices of Bitcoin (BTC), Ethereum (ETH), and Ripple (XRP) for the period of 01/09/2019 to 31/03/2020. The wavelet coherence analysis indicates that there is initially a negative relationship between the number of reported cases and deaths and Bitcoin; however, the relationship becomes positive in the later period. The findings for Ethereum and Ripple are also similar to the Bitcoin evidence, however, the interactions are weaker compared to Bitcoin. This shows the hedging role of cryptocurrencies against the uncertainty raised by COVID-19. In the beginning, their pricing behaved like that of traditional assets, but it starts to become a hedge as the effect of COVID-19 materializes. This is in line with previous studies that provide evidence on the hedging role of Bitcoin against uncertainty (Demir et al. 2018; Fang et al. 2019).

The rest of the paper is organized as follows. Section 2 briefly summarizes the studies examining the impact of COVID-19 on cryptocurrency market. Section 3 explains the data and methodology. Section 4 presents the results, and last section concludes the paper.

\section{Literature review}

Cryptocurrencies, especially Bitcoin, has attracted the attention of researchers and finance literature examines them in terms of efficiency, performance, hedging properties, and relationship with traditional financial assets. Likewise, studies exploring the impact of the recent pandemic on cryptocurrencies have emerged 
rapidly after the outbreak of COVID-19. By using two-moment value at risk, Conlon and McGee (2020) show that Bitcoin does not act as a safe haven and moves in a similar pattern with S\&P 500. When Bitcoin is included in the portfolio along with S\&P 500, downside risk of the portfolio increases significantly. This leads to a doubt on the ability of Bitcoin providing shelter from turbulence. Corbet et al. (2020) document sharp, short-term, dynamic correlations between Bitcoin and Chinese stock markets after the outbreak of COVID-19 pandemic. Conlon et al. (2020) focus on the safe haven properties of Bitcoin, Ethereum and Tether during the pandemic from the perspective of global stock market investors. They show that Bitcoin and Ethereum cannot be considered as a safe haven as the inclusion of those cryptocurrencies in the portfolios increases the downside risk. However, Tether, a peg to the US dollar, serves as a hedge during the COVID-19. Kristoufek (2020) argue that COVID-19 pandemic can be considered as a period of testing the safe haven abilities of Bitcoin. Using the quantile correlations of Bitcoin and S\&P500 and VIX Index, it is found that Bitcoin safe haven story is not valid while gold serves as a much better safe haven in the pandemic period. Lahmiri and Bekiros (2020) compare the behavior of cryptocurrencies with international stock markets during COVID-19. They find that cryptocurrencies are more affected by the pandemic than international stock markets. There is higher instability and higher irregularity in the cryptocurrency market compared to the equity market. Realized dynamic correlation analysis of Grobys (2020) shows that Bitcoin cannot hedge the extraordinary tail risk in US stocks. Those recent studies document that Bitcoin cannot be considered as a hedging instrument during the pandemic. However, Goodell and Goutte (2020) examine the comovement between Bitcoin and daily data of COVID-19 world deaths and show that after April 5, COVID-19 causes a rise in Bitcoin prices. In contrast to those studies, Yarovaya et al. (2020) explore the herding behavior in the cryptocurrency market. They show that COVID-19 does not significantly increase herding in the cryptocurrency market.

\section{Data and methodology}

\subsection{Data}

This paper aims to analyze the relationship between cryptocurrency prices and COVID19 pandemic. We use daily US\$ prices of Bitcoin (BTC), Ethereum (ETH), and Ripple (XRP). The market share of those cryptocurrencies is around $77 \%$ by the end of March 2020. The data period is from 01/09/2019 to 31/03/2020. We use worldwide COVID19 cases (WCC) and deaths from COVID-19 (WCD). Descriptive statistics of the variables are reported in Table 1. 


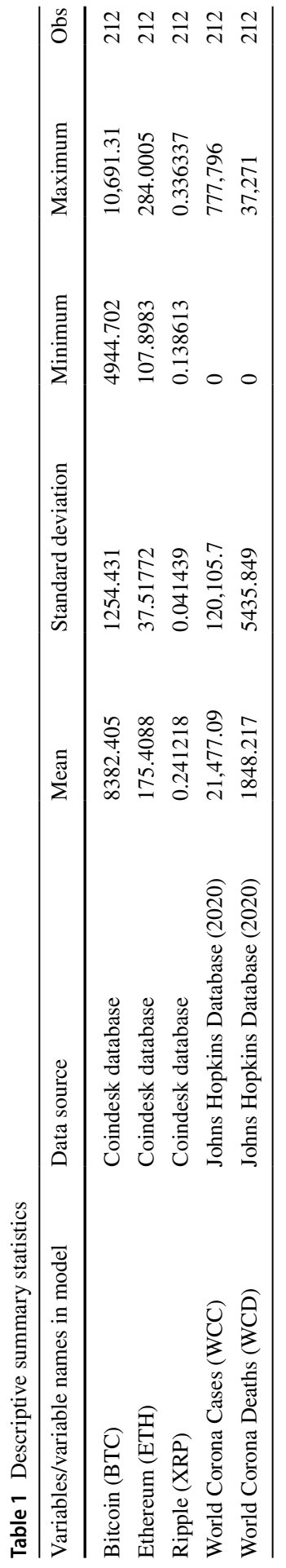




\subsection{ARDL analysis}

According to the unit root test (Zivot-Andrews 2002), ETH and XRP are stationary at level $(\mathrm{I}(0))$ while other variables are stationary at the first difference (I(1)). There are no structural breaks. In this situation, the most efficient model is ARDL (Autoregressive distributed lag) since the series are not second-order stationary. The ARDL model includes the series of autoregressive lags alongside with distributed lags and explains short and long-run relations (if series are co-integrated) (Pesaran and Shin 1998). The ARDL model can be written as follows:

$$
y_{t}=\alpha+\beta t+\sum_{t=1}^{p} \gamma y_{t-i}+\sum_{i=0}^{q} \theta x_{t-i}+\delta_{1} w_{t}+u_{t}
$$

where $\mathrm{p}$ is the number of lags of the dependent variables and $\mathrm{q}$ is the number of lags of independent variables. $\mathrm{x}$ represents the independent variable and $y$ represents the dependent variable. $\mathrm{u}$ is the error term. The orders of the ARDL models are selected by Akaike Information Criteria (AIC).

\subsection{Wavelet analysis}

Wavelet frequency analysis is a statistical method that analyzes the frequency and time axes using the rescaled series (Crowley, 2007). This method can be used to examine the wavelength with its frequencies and time scale. The time scale series in different level stationary conditions can be analyzed by this technique (Olayeni, 2016). Wavelet analysis is used commonly in geophysics and many other engineering branches (Torrence and Compo, 1998; Alexandridis and Zapranis, 2013; Massel, 2001), but it is also used in economics and finance in the recent years (Kim and In, 2005; Ko and Lee, 2015; Bouri et al. 2017). Cryptocurrency studies widely use wavelet analysis (Kristoufek, 2015; Kang et al. 2019). The wavelet analysis can transform series into continuous waves or signals with the help of some projections like Fourier transformations (Olayeni, 2016).

$$
\begin{gathered}
x(t)=\frac{1}{C_{\varphi}} \iint_{-\infty}^{+\infty} \varphi_{\tau, s}(t) W_{x}(\tau, s) \frac{d \tau d s}{d^{2}} \\
\widehat{\alpha_{j k}}=\sum_{h=1-n}^{n-1} \widehat{p}(h) \widehat{\varphi_{j k}}(2 \Pi h)=\sum_{h=1-n}^{n-1} \widehat{p}(h) \widehat{\varphi_{j k^{*}}}(2 \Pi h) \\
\widehat{f}(\omega)=(2 \Pi)^{-1} \sum_{j=0}^{j} \sum_{k=1}^{2^{J}} \widehat{a}_{j k} \psi_{j_{k}} \omega, \omega \in\left|-\tau_{1, \Pi}\right|
\end{gathered}
$$

In Eq. 2, data generation process is started by a reconstruction. In this reconstruction, series are transformed to synthetic data. Then, in Eqs. 3 and 4, series are 
transformed to a signal by wavelet transformation. Individual frequencies of the series can be analyzed by signal analysis. It is also suitable for multivariate analysis (Pakko, 2004). The co-movements of the two series can be expressed in wavelet coherence with the direction of the correlation between these two variables (Rua and Nunes, 2009). The wavelet coherence analysis is shown in Eq. 5.

$$
R_{x y}=\frac{\left|S\left(W_{x y}\right)\right|}{\left[S\left(\left|W_{x}\right|^{2}\right) S\left(\left|W_{y}\right|^{2}\right)\right]^{1 / 2}}
$$

Smoothing operator related to time and frequency and R-value vary between 0 and 1 (Aguiar-Conraria and Soares, 2011). In order to use Wavelet transformations as a first step the scale and frequencies of the series should be examined to decide which wavelet function and scale should be used. The selection of cone of interval is also important since every scale will be normalized in a wavelet function (Torrence and Compo, 1998). In the graphical explanation of the wavelet coherence analysis, arrows indicate phase differences. Arrows pointing to the right show a positive correlation and vice versa. Arrows indicate causality via phase differences between series (Kang et al. 2019). If the arrows point downwards, this means the first series leads the other one; if they point upwards, this means the second series leads the other one. Colors indicate the amount of correlation, where red is high, and blue is low (Vacha and Barunik 2012).

\section{Findings}

ARDL cointegration method has many advantages compared to other cointegration methods since it is suitable for analyzing variables at different order. It is also a more efficient estimator for small samples (Pesaran and Shin, 2001). We present the ARDL model estimations for each cryptocurrency in Table 2. For Bitcoin, short-run dynamics indicate that the lags of WCC affect BTC, but the direction of the second lag differs from the first and third lags, which is negative. For ETH, the signs of the coefficients are similar to BTC. We find that WCC has a positive effect and the first lag of WCC has a negative effect on XRP. When we use WCD as the independent variable, the results remain the same. After estimating the short-term in ARDL models, the existence of a similar long-term relationship is tested by bound test (Pesaran and Shin, 2001). In our models, the null hypothesis of "no long term relationship between variables" cannot be rejected. Since the directions of the effects of the distributed lags vary, we proceed with the wavelet decomposition procedure to identify the co-movements in more detail.

Figures 1, 2, 3 show the time and frequency domain scatters of the series used in the models. The figures show the power of the volatility of the series according to their normalized distribution. BTC has a higher volatility compared to ETH and XRP. 
Table 2 ARDL model results (short-run model)

\begin{tabular}{|c|c|c|c|c|c|c|}
\hline \multirow[b]{2}{*}{ Regressors } & \multicolumn{2}{|l|}{ BTC } & \multicolumn{2}{|l|}{ ETH } & \multicolumn{2}{|l|}{ XRP } \\
\hline & $\operatorname{ARDL}(1,3)$ & $\operatorname{ARDL}(1,3)$ & $\operatorname{ARDL}(1,3)$ & $\operatorname{ARDL}(1,3)$ & $\operatorname{ARDL}(1,1)$ & $\operatorname{ARDL}(1,3)$ \\
\hline \multirow{2}{*}{$\begin{array}{l}\text { BTC/ETH/ } \\
\text { XRP }(-1)\end{array}$} & $0.970 * * *$ & $0.966 * * *$ & $1.002 * * *$ & $0.995^{* * *}$ & $0.980 * * *$ & $0.968^{* * *} *$ \\
\hline & $(0.018)$ & $(0.017)$ & $(0.006)$ & $(0.018)$ & $(0.0189)$ & $(0.019)$ \\
\hline \multirow[t]{2}{*}{ WCC } & $0.022 * *$ & \multirow[t]{2}{*}{-} & $0.0009 * *$ & \multirow[t]{2}{*}{-} & $0.000007 * * *$ & \multirow[t]{2}{*}{-} \\
\hline & $(0.011)$ & & $(0.0003)$ & & $(0.000002)$ & \\
\hline \multirow[t]{2}{*}{ WCC $(-1)$} & $-0.058 * * *$ & \multirow[t]{2}{*}{ - } & $-0.002 * * *$ & \multirow[t]{2}{*}{ - } & $-0.000008^{* * *}$ & \multirow[t]{2}{*}{ - } \\
\hline & $(0.022)$ & & $(0.0006)$ & & $(0.00003)$ & \\
\hline \multirow[t]{2}{*}{$\mathrm{WCC}(-2)$} & $0.065 * * *$ & \multirow[t]{2}{*}{ - } & $0.0002 * * *$ & \multirow[t]{2}{*}{-} & \multirow[t]{2}{*}{ - } & \multirow[t]{2}{*}{-} \\
\hline & $(0.022)$ & & $(0.0006)$ & & & \\
\hline \multirow[t]{2}{*}{$\mathrm{WCC}(-3)$} & $-0.030 * *$ & \multirow[t]{2}{*}{ - } & $-0.001 * * *$ & \multirow[t]{2}{*}{-} & \multirow[t]{2}{*}{-} & \multirow[t]{2}{*}{-} \\
\hline & $(0.012)$ & & $(0.0003)$ & & & \\
\hline \multirow[t]{2}{*}{ WCD } & \multirow[t]{2}{*}{ - } & $0.552^{*}$ & \multirow[t]{2}{*}{ - } & $0.017 * *$ & \multirow[t]{2}{*}{ - } & $0.00002 *$ \\
\hline & & $(0.275)$ & & $(0.008)$ & & $(0.00095)$ \\
\hline \multirow[t]{2}{*}{$\mathrm{WCD}(-1)$} & \multirow[t]{2}{*}{ - } & $-1.769 * * *$ & \multirow[t]{2}{*}{ - } & $-0.048 * * *$ & \multirow[t]{2}{*}{ - } & $-0.00005^{* *}$ \\
\hline & & $(0.550)$ & & $(0.017)$ & & $(0.00002)$ \\
\hline \multirow[t]{2}{*}{$\mathrm{WCD}(-2)$} & \multirow[t]{2}{*}{ - } & $2.514 * * *$ & _- & $0.067 * * *$ & - & $0.00006^{* *}$ \\
\hline & & $(0.579)$ & & $(0.017)$ & & $(0.00002)$ \\
\hline $\mathrm{WCD}(-3)$ & _- & $-1.340 * * *$ & _- & $-0.037 * *$ & - & $-0.00003 * *$ \\
\hline & & $(0.340)$ & & $(0.010)$ & & $(0.00001)$ \\
\hline Constant & 247.602 & $287.817 *$ & -0.025 & 1.379 & 0.005 & $0.0081^{*}$ \\
\hline & (156.037) & $(47.863)$ & (3.418) & (3.328) & $(0.004)$ & $(0.004)$ \\
\hline Observation & 209 & 209 & 209 & 209 & 209 & 209 \\
\hline Wald stats & $28,753.97 * * *$ & $30,065.49 * * *$ & $14,356.25^{* * *}$ & $14,309.79$ & $1167.74 * * *$ & $21,232.689^{* * *}$ \\
\hline R-squared & 0.945 & 0.948 & 0.946 & 0.946 & 0.946 & 0.944 \\
\hline
\end{tabular}

Robust standard errors in parentheses. *Statistical significance at $10 \%$ level. **Statistical significance at $5 \%$ level.***Statistical significance at $1 \%$ level. Orders of the ARDL models are selected by Akaike Information Criteria (AIC). $(-1),(-2),(-3)$ denote one, two, and three days lag value of the related variable, respectively
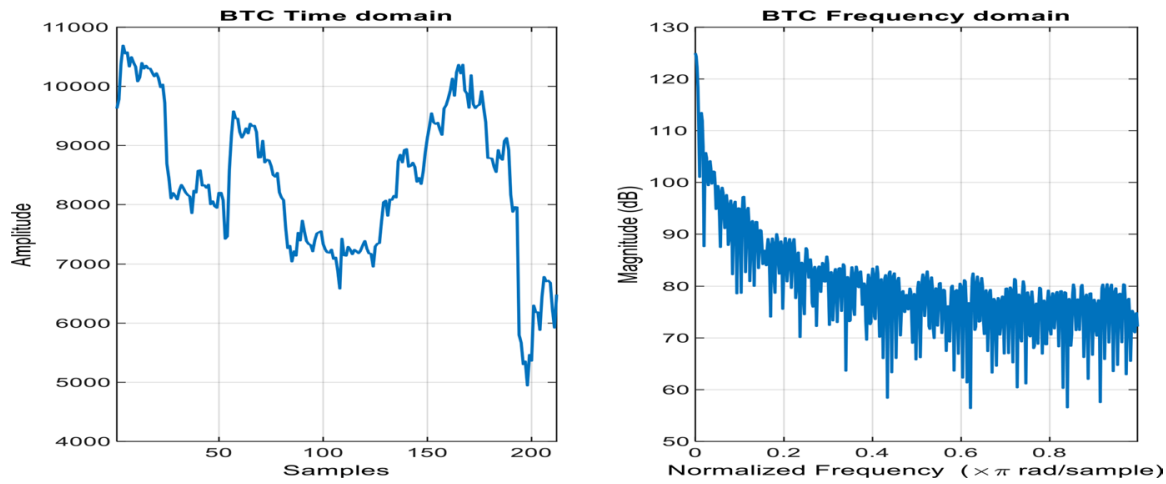

Fig. 1 Bitcoin prices time and frequency domain scatters 

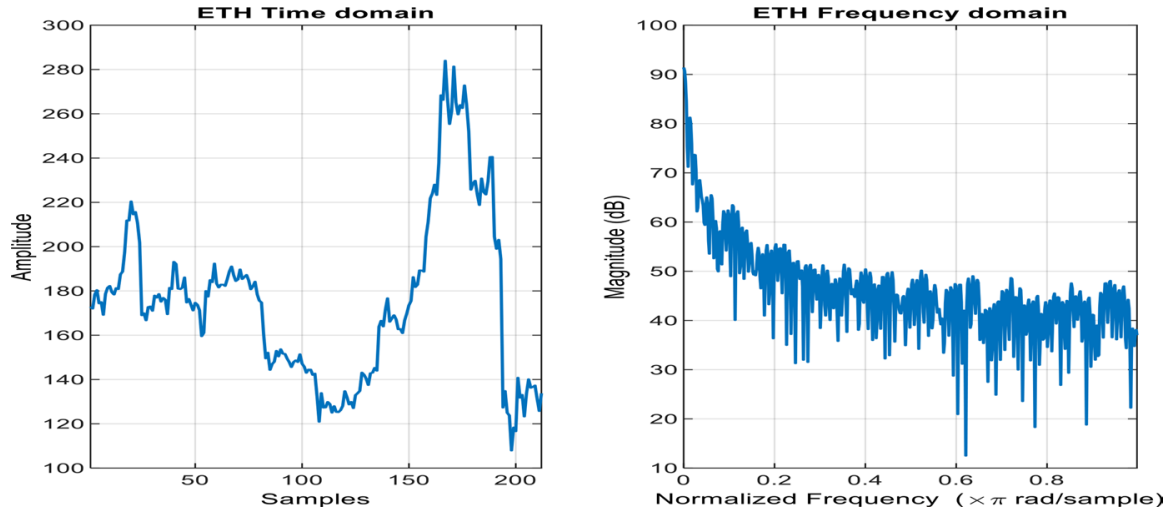

Fig. 2 Ethereum prices time and frequency domain scatters
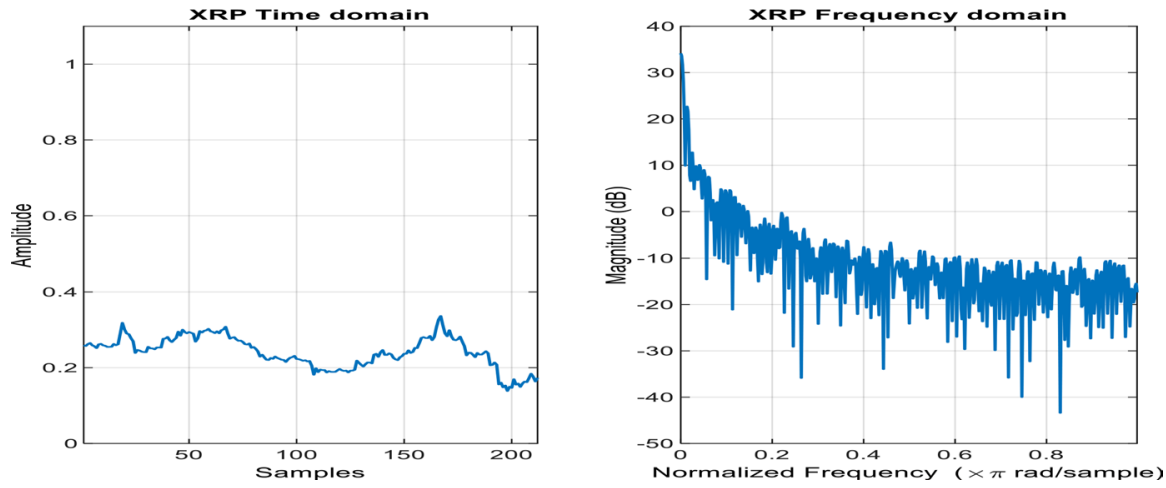

Fig. 3 Ripple prices time and frequency domain scatters

The movements of the series are tested by spectral and spectrum analysis using Fourier transforms. According to these tests, more breakpoints and a high frequency of wavelengths are observed. After analyzing individual signal decomposition, correlations of the series are examined with wavelet coherence analysis. Figure 4 shows the correlation matrix of all variables.

The wavelet coherence analyses for BTC are shown in Fig. 5a. In the WCC side of Fig. 5a, arrows pointing to the left indicate a negative relationship between BTC and WCC (0.008 and 0.02 interval frequency level, 0.9 coherence magnitude). It is also seen that this relationship turns positive in the last period of the series. We observe more co-movements at the WCD wavelet coherence graphs' upper right part (0.03 and 0.06 interval frequency level, 0.8 coherence magnitude) which means that the series has more impact on wavelet, especially during the last 55 days of the period we analyzed. Furthermore, the negative relationship turns positive during these 55 days. 


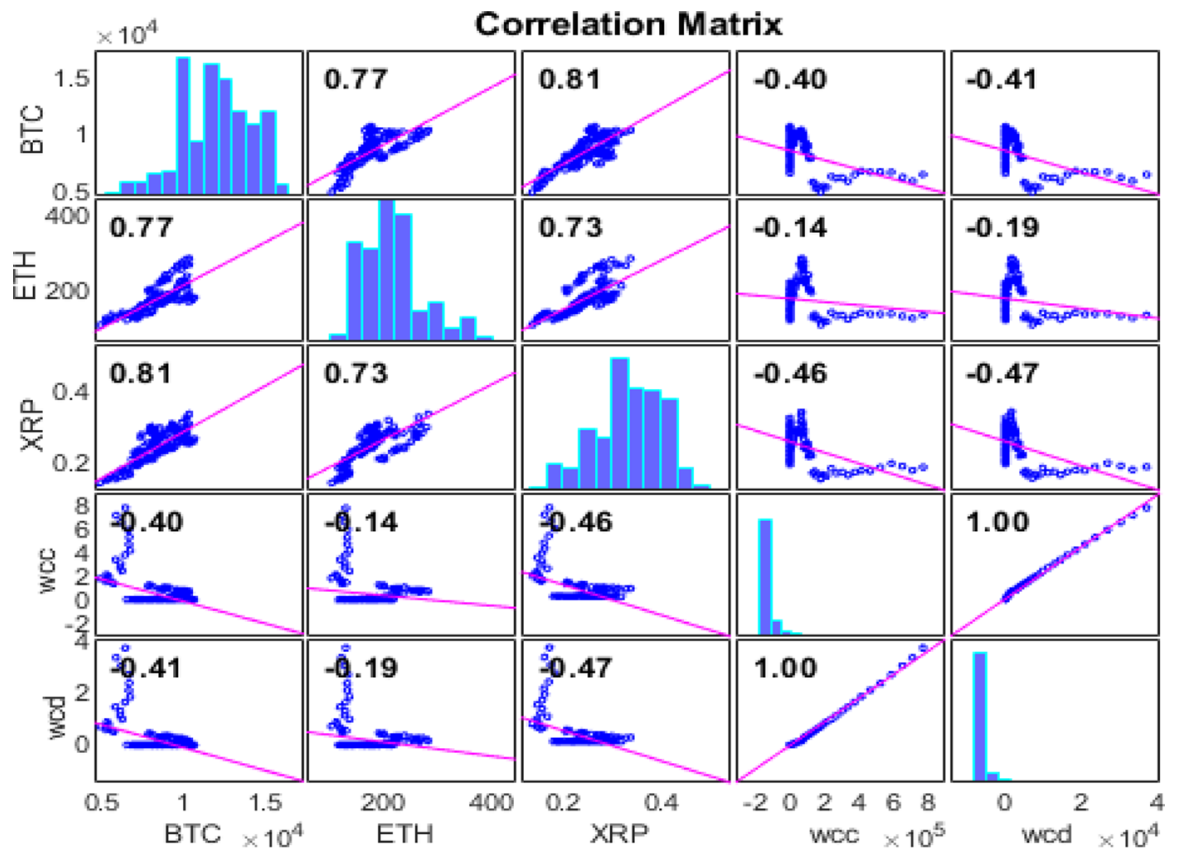

Fig. 4 Correlation matrix of all variables

When we observe the co-movements of ETH and WCC on the left side of Fig. 5b, we see less interaction compared to BTC. At the start of the observed period, the relationship is negative but later it turns to positive with high frequency $(0.125$ and 0.25 interval frequency level, 0.9 coherence magnitude).

Figure 5c shows the XRP's co-movements with WCC and WCD. Since the colors are colder (blue), it can be said that co-movements ( 0.7 coherence magnitude) are less intense compared to BTC and ETH. However, we observe another directional change from negative to positive $(0.125-0.25$ interval frequency level, 0.9 coherence magnitude) which is similar to the change that we see in Fig. 5a and b.

Our finding is in line with Goodell and Goutte (2020) who show that there is strong negative co-movement of Bitcoin prices and COVID-19 while after April 5, COVID-19 causes a rise in Bitcoin prices. However, we document contradictory results to Conlon and McGee (2020), Corbet et al. (2020), and Kristoufek (2020) as those studies show that Bitcoin has been a poor hedge against equity market during the COVID-19 pandemic.

\section{Conclusion}

We examine the relationship between cryptocurrencies (namely Bitcoin (BTC), Ethereum (ETH), and Ripple (XRP)) and COVID-19 cases/deaths. The wavelet coherence analysis indicates that there is a negative relationship between Bitcoin 

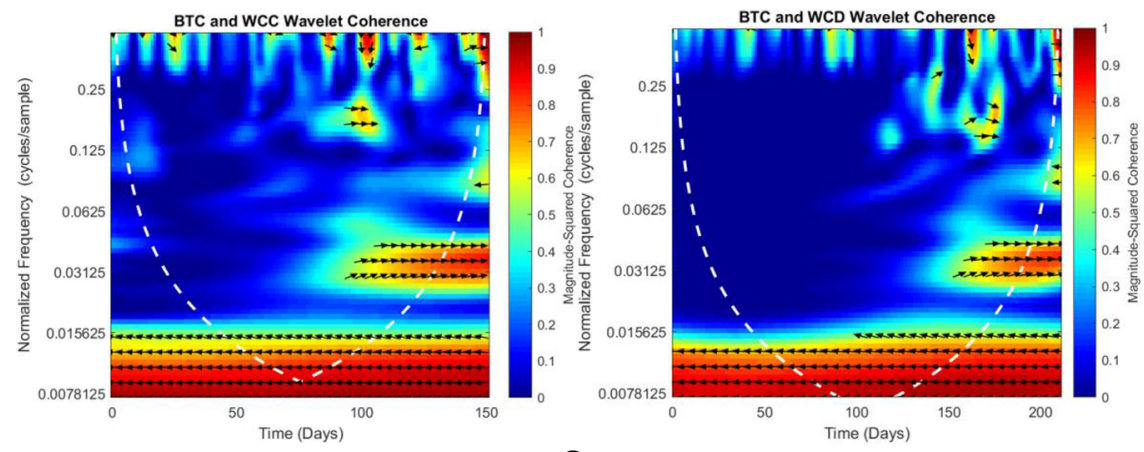

a
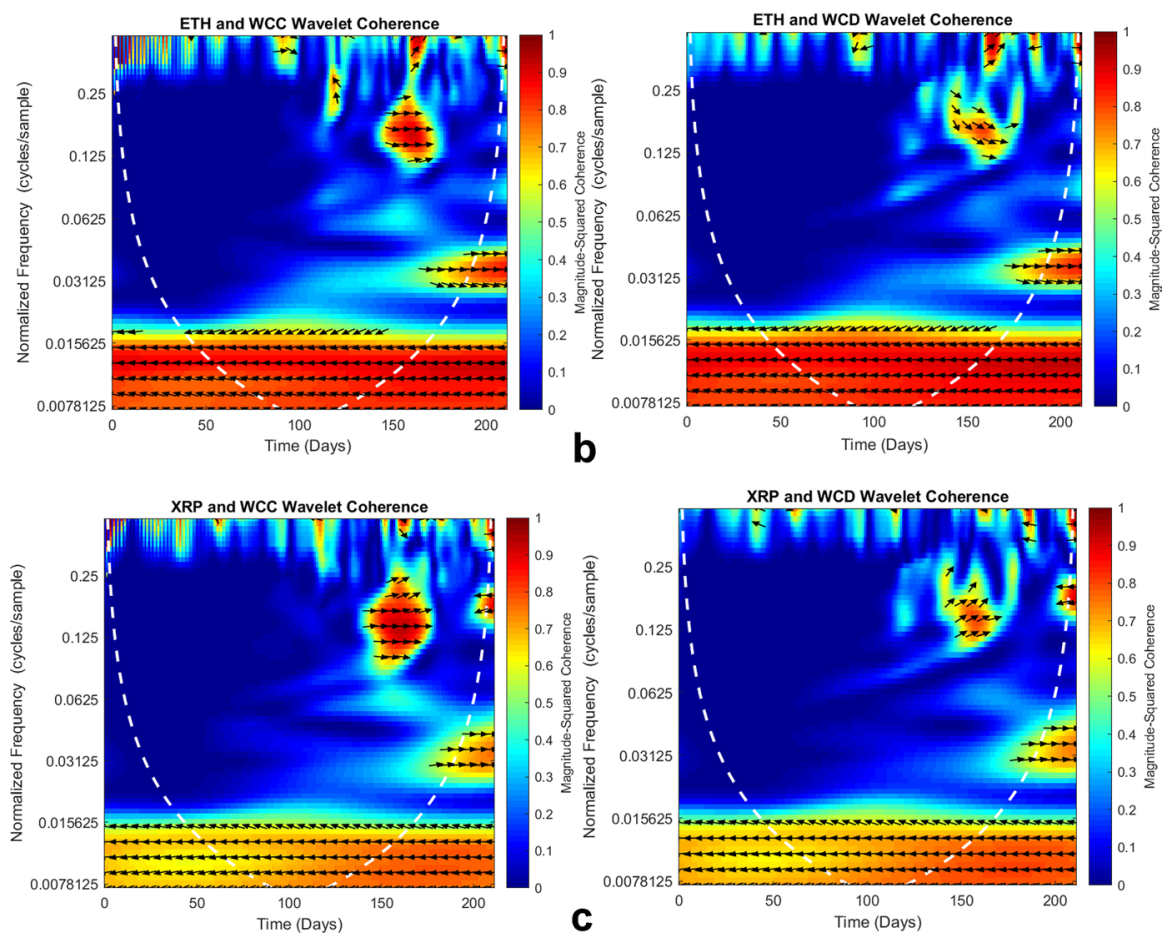

Fig. 5 a Wavelet Coherence BTC-WCC-WCD. b Wavelet Coherence ETH-WCC-WCD. c Wavelet Coherence XRP-WCC-WCD. BTC Bitcoin, ETH Ethereum, XRP Ripple, WCC and WCD represent global COVID-19 confirmed cases and deaths, respectively. In the graphical explanation of the wavelet coherence analysis colors indicate the magnitude and direction of correlation, where red is high coherence, and blue is low coherence. On the right side of the graphs, the scale is presented which is between 0 and 1. Interval cone white contours show confidence intervals for $95 \%$ at red or white noise processes. Confidence interval contours indicate the areas that should be focused while analyzing the graphs. Arrows indicate phase differences. Arrows pointing to the right show a positive correlation and vice versa. Arrows indicate causality via phase differences between series (Kang et al. 2019). If the arrows point downwards, this means the first series leads the other one; if they point upwards, this means the second series leads the other one 
value and number of reported cases and deaths; however, the relationship becomes positive during the later period. Wavelet coherence analysis results show that there is a causal relationship between COVID-19 and cryptocurrency prices. The findings for Ethereum and Ripple are also similar but with weaker interactions. This shows the hedging role of cryptocurrencies against the uncertainty raised by COVID-19. At the beginning, cryptocurrencies behave like the traditional assets, but they start to become a hedge as the effect of COVID-19 deepens. This is in line with previous studies that provide evidence on the hedging role of Bitcoin against uncertainty (Demir et al. 2018; Fang et al. 2019; Goodell and Goutte, 2020). As the number of reported cases and deaths rise, governments impose additional restrictions and those restrictions are likely to increase the demand for non-traditional assets. Bitcoin and Blockchain technology are theoretically capable of mitigating some of the issues that come with the new realities that the pandemic has brought. Investors should consider to include cryptocurrencies in their portfolios depending on the COVID-19 phases. Cryptocurrencies will not only provide benefits in terms of hedge against the pandemic, but they can also be used as a payment and money transfer instrument.

Further studies can examine the co-movement of traditional financial assets with the pandemic and compare the findings with the case of cryptocurrencies. Moreover, as the time passes, the number of observations will increase and it can provide new insights for the behavior of cryptocurrencies in the later stages of the pandemic.

\section{Compliance with ethical standards}

Conflict of interest On behalf of all authors, the corresponding author states that there is no conflict of interest.

\section{References}

Aguiar-Conraria, L., \& Soares, M. J. (2011). Oil and the macroeconomy: Using wavelets to analyze old issues. Empirical Economics, 40(3), 645-655.

Al-Awadhi, A. M., Alsaifi, K., Al-Awadhi, A., \& Alhammadi, S. (2020). Death and contagious infectious diseases: Impact of the COVID-19 virus on stock market returns. Journal of Behavioral and Experimental Finance, 27, 1-5.

Alexandridis, A. K., \& Zapranis, A. D. (2013). Wavelet neural networks: A practical guide. Neural Networks, 42, 1-27.

Bouri, E., Gupta, R., Tiwari, A. K., \& Roubaud, D. (2017). Does Bitcoin hedge global uncertainty? Evidence from wavelet-based quantile-in-quantile regressions. Finance Research Letters, 23, 87-95.

Conlon, T., \& McGee, R. (2020). Safe haven or risky hazard? Bitcoin during the COVID-19 bear market. Finance Research Letters, 35, 101607.

Conlon, T., Corbet, S., \& McGee, R. J. (2020). Are cryptocurrencies a safe haven for equity markets? An international perspective from the COVID-19 pandemic. Research in International Business and Finance, 54, 101248.

Corbet, S., Larkin, C., \& Lucey, B. (2020). The contagion effects of the covid-19 pandemic: Evidence from gold and cryptocurrencies. Finance Research Letters, 35, 101554.

Crowley, P. (2007). A guide to wavelets for economists. Journal of Economic Surveys, 21, 207-264.

Demir, E., Gozgor, G., Lau, C. K. M., \& Vigne, S. A. (2018). Does economic policy uncertainty predict the Bitcoin returns? An empirical investigation. Finance Research Letters, 26, 145-149. 
Fang, L., Bouri, E., Gupta, R., \& Roubaud, D. (2019). Does global economic uncertainty matter for the volatility and hedging effectiveness of Bitcoin? International Review of Financial Analysis, 61, 29-36.

Goodell, J.W., \& Goutte, S. (2020). Co-movement of COVID-19 and Bitcoin: Evidence from wavelet coherence analysis. Finance Research Letters, forthcoming

Grobys, K. (2020). When Bitcoin has the flu: On Bitcoin's performance to hedge equity risk in the early wake of the COVID-19 outbreak. Applied Economics Letters, forthcoming.

Kang, S. H., McIver, R. P., \& Hernandez, J. A. (2019). Co-movements between Bitcoin and Gold: A wavelet coherence analysis. Physica A: Statistical Mechanics and Its Applications, 536, 1-9.

Kim, S., \& In, F. (2005). The relationship between stock returns and inflation: new evidence from wavelet analysis. Journal of Empirical Finance, 12(3), 435-444.

Ko, J. H., \& Lee, C. M. (2015). International economic policy uncertainty and stock prices: Wavelet approach. Economics Letters, 134, 118-122.

Kristoufek, L. (2015). What are the main drivers of the Bitcoin price? Evidence from wavelet coherence analysis. PloS one, 10(4), 1-15.

Kristoufek, L. (2020). Grandpa, grandpa, tell me the one about Bitcoin being a safe haven: Evidence from the COVID-19 pandemics. https://arxiv.org/pdf/2004.00047.pdf

Lahmiri, S., \& Bekiros, S. (2020). The impact of COVID-19 pandemic upon stability and sequential irregularity of equity and cryptocurrency markets. Chaos, Solitons and Fractals, 138, 109936.

Massel, S. R. (2001). Wavelet analysis for processing of ocean surface wave records. Ocean Engineering, 28(8), 957-987.

Olayeni, O. R. (2016). Causality in continuous wavelet transform without spectral matrix factorization: Theory and application. Computational Economics, 47, 321-340.

Onali, E. (2020). COVID-19 and stock market volatility. Available at SSRN: https://ssrn.com/abstr act=3571453 or https://doi.org/10.2139/ssrn.3571453.

Pakko, M. (2004). A spectral analysis of the cross-country consumption correlation puzzle. Economics Letters, 84, 341-347.

Pesaran, M. H., \& Shin, Y. (1998). An autoregressive distributed-lag modelling approach to cointegration analysis. Econometric Society Monographs, 31, 371-413.

Pesaran, M. H., Shin, Y., \& Smith, R. J. (2001). Bounds testing approaches to the analysis of level relationships. Journal of Applied Econometrics, 16, 289-326.

Rua, A., \& Nunes, L. C. (2009). International co-movement of stock market returns: A wavelet analysis. Journal of Empirical Finance, 16, 632-639.

Torrence, C., \& Compo, G. P. (1998). A practical guide to wavelet analysis. Bulletin of the American Meteorological Society, 79(1), 61-78.

Vacha, L., \& Barunik, J. (2012). Co-movement of energy commodities revisited: Evidence from wavelet coherence analysis. Energy Economics, 34, 241-247.

Yarovaya, L., Matkovskyy, R., \& Jalan, A. (2020). The effects of a 'Black Swan' event (COVID-19) on herding behavior in cryptocurrency markets: Evidence from cryptocurrency USD, EUR, JPY and KRW Markets. SSRN: https://ssrn.com/abstract=3586511.

Zaremba, A., Kizys, R., Aharon, D. Y., \& Demir, E. (2020). Infected markets: Novel coronavirus, government interventions, and stock return volatility around the globe. Finance Research Letters, 35, 1-7.

Zhang, D., Hu, M., \& Ji, Q. (2020). Financial markets under the global pandemic of COVID-19. Finance Research Letters, in press.

Zivot, E., \& Andrews, D. W. K. (2002). Further evidence on the great crash, the oil-price shock, and the unit-root hypothesis. Journal of Business and Economic Statistics, 20, 25-44.

Publisher's Note Springer Nature remains neutral with regard to jurisdictional claims in published maps and institutional affiliations. 